\title{
The Impact of Cumulus Parameterization Schemes on the Simulation of Tropical Cyclone "Roanu" Over the Bay of Bengal Using WRF Model
}

\author{
Saifullah $^{1 *}$, Md. Idris Ali ${ }^{1}$ and Ashik Imran ${ }^{2}$ \\ ${ }^{I}$ Department of Physics, Khulna University of Engineering \& Technology, Khulna-9203, Bangladesh \\ ${ }^{2}$ Department of Physics, University of Dhaka, Dhaka-1000, Bangladesh
}

(Received : 23 September 2019 ; Accepted : 7 January 2020)

\begin{abstract}
A sensitivity study has been made on cumulus parameterization (CP) schemes of Weather Research and Forecasting (WRF) model for the simulation of tropical cyclone Roanu which formed over Bay of Bengal during May 2016. The model was run for 72 hours with different CP schemes such as Kain-Fritsch (KF), Betts-Miller-Janjic (BMJ), Grell-Freit as Ensemble (GFE), Grell 3D Ensemble (G3E) and Grell-Devenyi (GD) Ensemble schemes to study the variation in track, intensity. The landfall position error is minimum for BMJ scheme but the time delayed only 1.5-5 hours for all schemes except GD scheme. The Root Mean Square Error (RMSE) and Mean Absolute Error (MAE) of minimum sea level pressure and maximum wind speed is smaller for BMJ, GFE, GD schemes. The RMSE-MAE of rainfall is minimum for BMJ and G3E schemes. Except GD scheme all the other schemes give the better result.
\end{abstract}

Keywords: Tropical cyclone, Bay of Bengal, Cumulus parameterization scheme, RMSE, MAE.

\section{Introduction}

Tropical cyclones (TCs) are the biggest hazardous exhibitions of multi-scale structured convection on the Earth as well as the Indian sub-continent. It causes the massive loss of life and destruction of the physical infrastructure near the inshore areas where actually the landfall of the TC is located ${ }^{1}$. These TCs shows their most devastating nature when the three main hazards such as forceful winds, massive rain and storm surges are combined together with them ${ }^{2}$. It has the serious influences on social and economic conditions of any nations such as Bangladesh, India and Myanmar which adjoining the Bay of Bengal $(\mathrm{BoB})^{3}$. Based on the average wind speed, the cyclonic storms are categorized by India Meteorological Department (IMD) into various classes. If the wind speed is about less than 14, 15-17, 18-24, 25-32, 33-61 and greater than $61 \mathrm{~ms}^{-1}$ then this situation is known as the Depression, Deep depression, Cyclonic storm, Severe cyclonic storm, Very severe cyclonic storm and Super cyclonic storm respectively ${ }^{4}$.The TC is formed generally over the warm tropical oceans and when the favorable environmental conditions are available it travels on the way to land throughout the period of pre-monsoon (March-May) and post-monsoon (October-November) seasons ${ }^{5,}{ }^{6}$. Almost seven percent of the overall amount of tropical storms worldwide yearly is formed over the $\mathrm{BoB}$, that's why this $\mathrm{BoB}$ is known as the actually active area for the improvement of cyclonic storms ${ }^{7}$.

In previous years many researchers have done their research work about the simulation of TC and also discuss about the cumulus parameterization (CP) schemes and their effects on the TC simulation.Wang and Seaman ${ }^{8}$ found that, the KF scheme shows better efficiency and has a meaningful importance in case of the variation of warm and cold period. Also the wet convective downdrafts are mainly caused by this scheme. Mandal et al. ${ }^{7}$ found that, when the Hong-Pan PBL scheme is combined with Grell or BMJ-CP schemes, the higher performance is appeared with respect to the other arrangements. Islam et al. ${ }^{9}$ has observed from their study is that, the WSM3 and WDM5 schemes give the better prediction of slowly intensifying TC Mora. Litta et al. ${ }^{10}$ found that, the GD scheme shows the best performance to simulate the action of thunderstorm as well as the intensity, time and area of incidence than the other convective schemes. Osuri et al. ${ }^{11}$ has found the well forecast of intensity, track, and rainfall associated with TC by the YSU-KF (YKF) combination, because this combination has formed strong horizontal wind speed, resilient convergence with strong updrafts inside the warmer cyclone core. Mohandas and Ashrit ${ }^{12}$ found that the track, intensification and related rainfall distribution are well simulated by KF and poorest for GD scheme.

On the basis of various conventions many scientists/ researchers have been advanced a number of parameterization schemes, although these schemes have several restrictions in the forecast of the intensity distribution and track pattern of TCs. Amongst them the CP schemes are liable for the sub-grid-scale consequences of convective and surface clouds ${ }^{13}$. The schemes are aimed to exhibit upright fluidities because of uncertain upward air currents and downward air currents. They conduct simply on separate columns where the scheme is generated and deliver upright warming and saturating profiles. The CP schemes are ideally effective for simply thicker grid sizes (i.e., $>10 \mathrm{~km}$ ), where they essential to appropriately release latent heat on a convincing time range in the convective columns. Where the conventions in regard to the convective whirlpools being completely sub-grid-scale failure for bigger grid dimensions, occasionally these schemes are suitable for generating convection in $5-10 \mathrm{~km}$ grid applications ${ }^{14}$.

The principal objective of our present research work is to inspect the influence of $\mathrm{CP}$ schemes on the simulation of TC 'Roanu' or to investigate the intensity and track

*Author for correspondence. e-mail: saifullahphdu@gmail.com 
pattern of TC 'Roanu' which formed during May 2016 over the BoB with Weather Research and Forecasting (WRF) model.

\section{Synoptic Situation of Tropical Cyclone Roanu}

The BoB experienced a TC Roanu which was the first seasonal tropical storm in the year of 2016. At the time of 0300 UTC of 15 May 2016, a low-pressure zone is raised over southwest Bay and neighboring regions of Sri Lanka. On 17 May 2016 this low-pressure zone is deepen into a depression and then deep depression. On 19 May 2016 it strengthened into a cyclonic storm (CS) 'Roanu' over WestCentral Bay and adjacent southwestern Bay. Firstly, it progressed north northeastern direction and then northeastwards over North Bay and lastly, it crossing over the Barisal-Chittagong coast near Chittagong for the period of 0600 to 1100 UTC of 21 May 2016. It produced landslide and strong flood, also more than 101 people were departed and dislocated above 1, 34,000 persons in Sri Lanka. Tamil Nadu, Andhra Pradesh, Kerala and Odisha have experienced aheavy precipitation due to TC Roanu. No expiry news was found in these Indian regions. Total 1,10,684 families were partly and 29,168 wholly attacked by the TC Roanu and 24 persons are died and 2 were stated missing in Bangladesh ${ }^{15}$.

\section{Numerical Model Description}

The WRF model (version 3.8.1) is well known mesoscale model which have been selected for our current research work.With the cooperation of various organizations such as National Oceanic and Atmospheric Administration (NOAA) and National Center for Environmental Prediction (NCEP) and several institutions of higher education, the model was promoted at National Center for Atmospheric Research (NCAR). This is a non-hydrostatic mesoscale model planned for forecasting of short-range atmospheric occurrences, highlighting horizontal grid distances of a few kilometers or less ${ }^{14}$. It is impractical to investigate all CP schemes in such kind of research work. Five have been nominated because of their extensive practice in the numerical based models and the representative behavior about different closure conventions and scale deliberations. The Kain-Fritsch

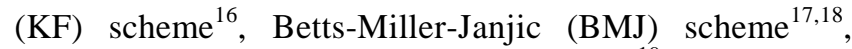
Grell-Freitas Ensemble (GFE) scheme ${ }^{19}$, Grell 3D

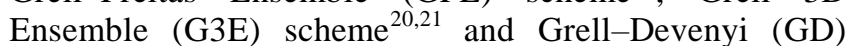
Ensemble scheme ${ }^{21}$ are the five $\mathrm{CP}$ schemes which are frequently used worldwide as selected for assessment. All of these schemes are promoted with the help of the previous simplified parameterization schemes. WRF Double-Moment 6-class (WDM6) scheme $^{22}$ is only the microphysics (MP) scheme which have been used in this study. The Terrain following hydrostatic pressure is the vertical coordinate of the model and the horizontal grid of the model is Arakawa C-grid staggering. Monin-Obukhov similarity theory scheme have been used for surface layer and Yonsei University (YSU) scheme have been used for planetary boundary layer (PBL). Dudhia scheme and
Rapid Radiative Transfer Model (RRTM) have been introduced in this model as a short wave and long wave radiation respectively.

Table 1. The complete conformation of the WRF model dynamics and physics.

\begin{tabular}{|c|c|c|c|}
\hline WRF core & ARW & $\begin{array}{l}\text { Time } \\
\text { integration }\end{array}$ & $\begin{array}{l}3^{\text {rd }} \quad \text { order } \\
\text { Runge-Kutta }\end{array}$ \\
\hline $\begin{array}{l}\text { Number of } \\
\text { domain }\end{array}$ & 1 & $\begin{array}{l}\text { Initial } \\
\text { condition }\end{array}$ & $\begin{array}{l}\text { 3D real-data } \\
\left(\mathrm{FNL}: 1^{\circ} \times 1^{\circ}\right)\end{array}$ \\
\hline $\begin{array}{l}\text { Centre of } \\
\text { Domain }\end{array}$ & $\begin{array}{l}17.5^{\circ} \mathrm{N} \\
87.5^{\circ} \mathrm{E}\end{array}$ & $\begin{array}{l}\text { Lateral } \\
\text { boundary } \\
\text { condition }\end{array}$ & $\begin{array}{l}\text { Specified } \\
\text { options for } \\
\text { real-data }\end{array}$ \\
\hline $\begin{array}{l}\text { Horizontal } \\
\text { grid distance }\end{array}$ & $9 \mathrm{~km}$ & $\begin{array}{l}\text { Diffusion } \\
\text { and } \\
\text { Damping }\end{array}$ & $\begin{array}{l}\text { Simple } \\
\text { Diffusion }\end{array}$ \\
\hline $\begin{array}{l}\text { Integration } \\
\text { time steps }\end{array}$ & $36 \mathrm{~s}$ & CP schemes & $\begin{array}{l}\text { KF, BMJ, } \\
\text { GFE, G3E, GD }\end{array}$ \\
\hline $\begin{array}{l}\text { Number of } \\
\text { grid points }\end{array}$ & $120 \times 120 \times 30$ & MP & WDM6 \\
\hline $\begin{array}{l}\text { Map } \\
\text { projection }\end{array}$ & Mercator & PBL & YSU \\
\hline $\begin{array}{l}\text { Horizontal } \\
\text { grid }\end{array}$ & $\begin{array}{l}\text { Arakawa C- } \\
\text { grid }\end{array}$ & $\begin{array}{l}\text { Surface layer } \\
\text { physics }\end{array}$ & $\begin{array}{l}\text { Monin } \\
\text { Obukhov } \\
\text { similarity } \\
\text { theory }\end{array}$ \\
\hline $\begin{array}{l}\text { Vertical co- } \\
\text { ordinate }\end{array}$ & $\begin{array}{l}30 \text { sigma } \\
\text { levels }\end{array}$ & $\begin{array}{l}\text { Radiation } \\
\text { schemes }\end{array}$ & $\begin{array}{l}\text { Dudhia short } \\
\text { wave, RRTM } \\
\text { long wave }\end{array}$ \\
\hline
\end{tabular}

\section{Data and Methodology}

For initial and lateral boundary conditions the National Centre for Environmental Prediction (NCEP) higher resolution Global Final (FNL) analysis data was used in this present study. This FNL data cover the whole world every six hours with $1.0^{\circ} \times 1.0^{\circ}$ grids. For the investigation of the intensity distribution and track pattern of TC Roanu, the model was run for $72 \mathrm{~h}$ from 0000 UTC of 19 May to 0000 UTC of 22 May 2016. The IMD obtained data of track patterns have been used for making a comparison or validation with the model simulated track.The intensity of TC Roanu with respect to the simulated Minimum Sea Level Pressure (MSLP) and Maximum Wind Speed (MWS) is studied and validated with IMD observed data. The model configuration has been made with single domain of $9 \mathrm{~km}$ horizontal grid distance. Generally, the CP schemes are suitable for horizontal grid distance of greater than $10 \mathrm{~km}$ but occasionally effective for 5 to $10 \mathrm{~km}$ grid distance ${ }^{14}$. Mallik et al. ${ }^{23}$ also used $9 \mathrm{~km}$ horizontal resolution and found better results. The number of grid points in the eastwest direction is 120 and north-south direction is 120 and vertical levels are 30 . The computational stability of the model was maintained by using $3^{\text {rd }}$ order Runge-Kutta time integration scheme and by setting the time step of integration of 36 seconds. The WRF model output gives the ctl file and which is converted into txt format data 
with the help of Grid Analysis and Display System (GrADS). The txt format data then transformed into Microsoft Excel format and finally drawinga graph with the help of Excel. Also, the latent heat flux (LHF) at the surface, convective available potential energy (CAPE), accumulated total cumulus rainfall and water vapor mixing ratio (WVMR) at $850 \mathrm{hPa}$ level have been simulated and analyzed during the intensification and movement of TC Roanu. A complete conformation of the WRF model dynamics and physics are given in Table 1.

\section{Results and Discussions}

The results of these parameter (i.e., intensity as well as MSLP and MWS, LHF, CAPE, rainfall, WVMR) and the analysis of track of TC Roanu have been given and discussed in the subsequent sections.

\section{Track of TC Roanu}

The IMD observed and WRF model simulated 72 hours track forecast of TC Roanu for five different CP schemes valid for 0000 UTC of 19 May to 0000 UTC of 22 May 2016 is displayed in Fig.1.

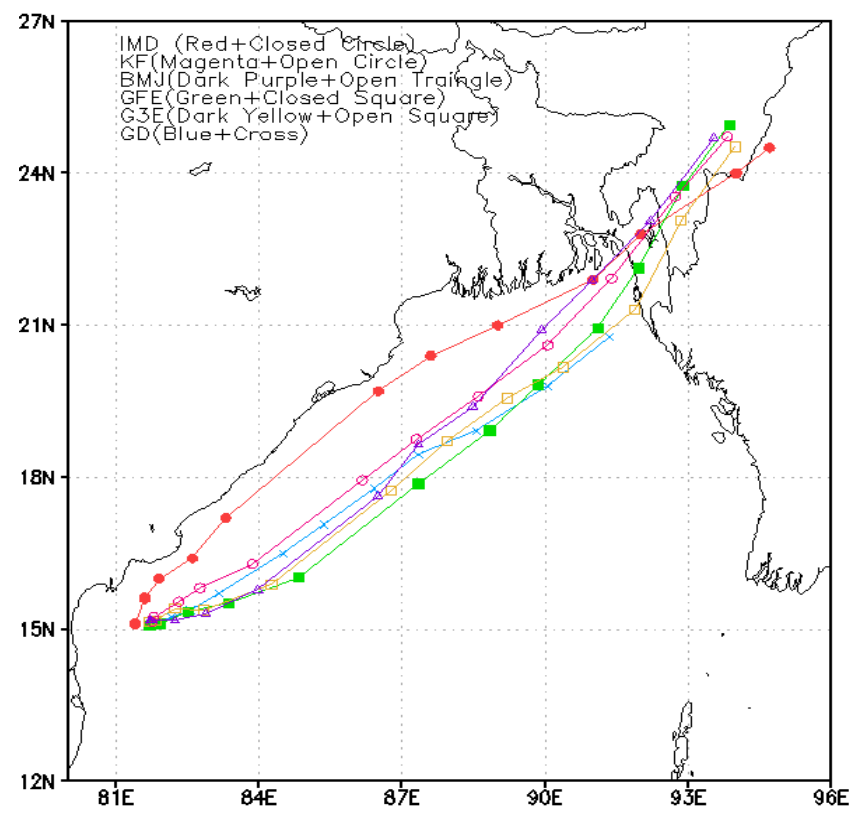

Fig. 1. The IMD observed and WRF model simulated 72 hours track forecast of TC Roanu for five different CP schemes starting from 0000 UTC of 19 May to 0000 UTC of 22 May 2016.

The model simulated track pattern for 72 hours prediction is parallel to the observed track but it is deviated east side of the observed track. The IMD observed landfall position is $22.45^{\circ} \mathrm{N} \& 91.67^{\circ} \mathrm{E}$ which is found at $1000 \mathrm{UTC}$ of 21 May. The landfall positions were $22.27^{\circ} \mathrm{N} \& 91.83^{\circ} \mathrm{E}, 22.55^{\circ} \mathrm{N} \&$ $91.50^{\circ} \mathrm{E}, 21.84^{\circ} \mathrm{N} \& 91.89^{\circ} \mathrm{E}$ and $21.30^{\circ} \mathrm{N} \& 92^{\circ} \mathrm{E}$ which were found at 1330, 1500, 1130 and 1230 UTC of 21 May for KF, BMJ, GFE and G3E schemes respectively. During the study period GD scheme can't simulate landfall time and position. After the landfall time the track pattern slightly moves to northeast of the observed track for all the schemes except GD scheme. Fig. 2 shows the variation of track error with time for five different $\mathrm{CP}$ schemes. From this figure it is found that the track error is maximum for GD scheme for most of the time.

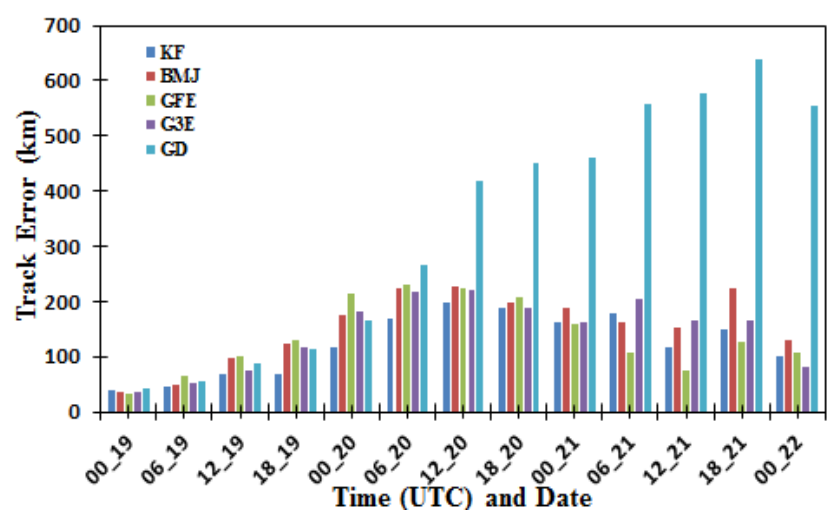

Fig. 2. The variation of track error with time for five different $\mathrm{CP}$ schemes.

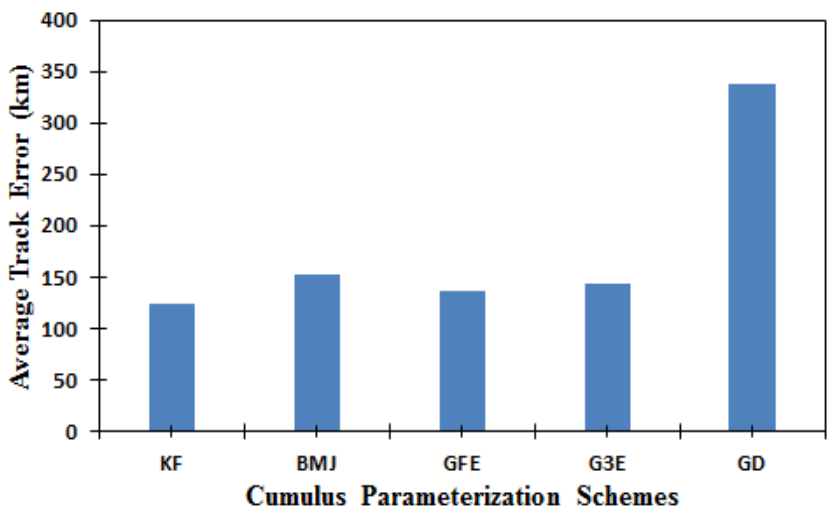

Fig. 3. The variation of average track error with five different $\mathrm{CP}$ schemes.

Also, the average track error for different $\mathrm{CP}$ schemes is shown in Fig. 3. The average track error 123.20, 153.10, $136.72,142.96$ and $338 \mathrm{~km}$ are found for KF, BMJ, GFE, G3E and GD schemes respectively. The average track error is found maximum for GD scheme and minimum for $\mathrm{KF}$ scheme. The landfall position error and time error is shown in Table 2. The landfall position error is found 26.73, 21.89, 71.97 and $132.80 \mathrm{~km}$ for KF, BMJ, GFE and G3E schemes respectively. The landfall position error are minimum for $\mathrm{BMJ}$ and $\mathrm{KF}$ schemes, so the landfall position is much closer to the observed landfall position for these two CP schemes. The time of landfall was delayed at least 3.5, 5.0, 1.5 and 2.5 hours for KF, BMJ, GFE and G3E schemes respectively than that of the IMD observed landfall time. The landfall time for GFE scheme is closer to the observed landfall time. From the analysis of average track error, landfall position error and time error it is concluded that, though, there are some errors in the locations with respect to time which displays few delays in landfall but all the schemes are very much capable to found the right track of TC Roanu except GD scheme. 
Table 2. Observed and model simulated landfall time of TC Roanu, landfall position, landfall position error and time error for different $\mathrm{CP}$ schemes (D*=Delayed of landfall).

\begin{tabular}{|c|c|c|c|c|}
\hline $\begin{array}{l}\mathrm{CP} \\
\text { schemes }\end{array}$ & $\begin{array}{l}\text { Landfall } \\
\text { time }\end{array}$ & $\begin{array}{l}\text { Position } \\
\text { (lat. }{ }^{0} \text { N/lon. }{ }^{0} \text { E) }\end{array}$ & $\begin{array}{l}\text { Landfall } \\
\text { position } \\
\text { error } \\
(\mathrm{km})\end{array}$ & $\begin{array}{l}\text { Time } \\
\text { error } \\
\text { (hours) }\end{array}$ \\
\hline $\mathrm{KF}$ & $\begin{array}{l}1330 \\
\text { UTC of } \\
21 \text { May }\end{array}$ & $22.27 / 91.83$ & 26.73 & $3.5 \mathrm{D}^{*}$ \\
\hline BMJ & $\begin{array}{l}1500 \\
\text { UTC of } \\
21 \text { May }\end{array}$ & $22.55 / 91.50$ & 21.89 & $5.0 \mathrm{D} *$ \\
\hline GFE & $\begin{array}{l}130 \\
\text { UTC of } \\
21 \text { May } \\
\end{array}$ & $21.84 / 91.89$ & 71.97 & $1.5 \mathrm{D}^{*}$ \\
\hline G3E & $\begin{array}{l}1230 \\
\text { UTC of } \\
21 \text { May }\end{array}$ & $21.30 / 92.00$ & 132.80 & $2.5 \mathrm{D}^{*}$ \\
\hline Observed & $\begin{array}{l}1000 \\
\text { UTC of } \\
21 \text { May }\end{array}$ & $22.45 / 91.67$ & & \\
\hline
\end{tabular}

Intensity of TC Roanu

The intensity of the TC Roanu is discussed with respect to the Minimum Sea Level Pressure (MSLP) and Maximum Wind Speed (MWS).

\section{Minimum Sea Level Pressure (MSLP)}

The time variation of observed and model simulated MSLP (hPa) of TC Roanu using KF, BMJ, GFE, G3E and GD schemes is shown in Fig. 4. The low-pressure area development is a vital preliminary situation for the probable meteorological disorders. If the suitable conditions are present, then this disturbance strengthen into a TC. So, the MSLP has a very good significance for the measurement of the intensity of a $\mathrm{TC}^{23,3}$. The IMD observed and model simulated MSLP slowly decreases with the passage of time. The MSLP reaches the lowest value or gets the highest intensity just near the landfall time of the system and after that it increases with time except GD scheme.The IMD observed MSLP is $983 \mathrm{hPa}$ at 0600 UTC of 21 May 2016. The model simulated MSLP of 942, 962, 950, 949 and 972 $\mathrm{hPa}$ are found at 1200,1200, 0000, 1200 and $0000 \mathrm{UTC}$ of 21 May 2016 for KF, BMJ, GFE, G3E and GD schemes respectively. With respect to the IMD observed value the pressure departures are found minimum for GD scheme and maximum for KF scheme. The simulated pressure drops for all $\mathrm{CP}$ schemes indicate that the system has achieved the intensity of cyclonic storm. The IMD observed intensity is much lower than that of the model simulated intensity in terms of pressure drop.

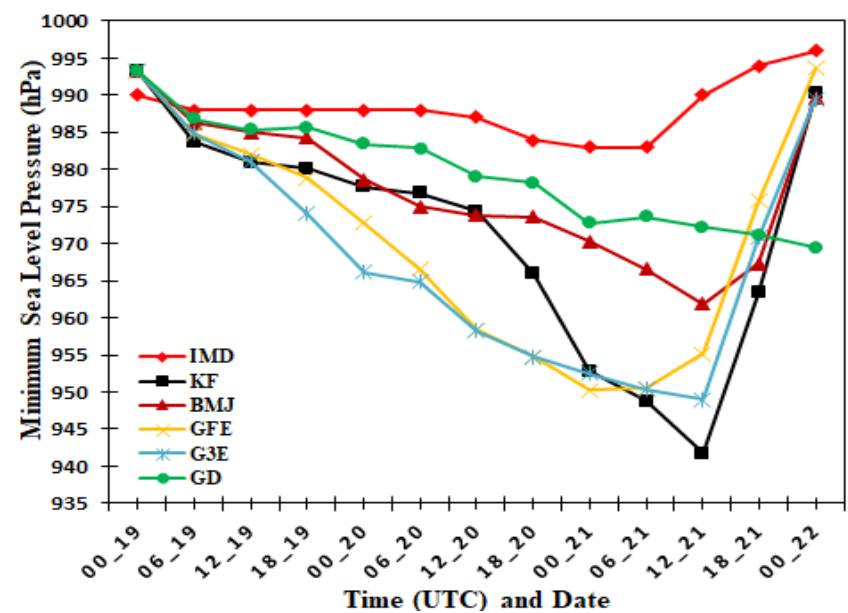

Fig. 4. Variation of observed and model simulated MSLP (hPa) with time for five different $\mathrm{CP}$ schemes.

\section{Maximum Wind Speed (MWS)}

The time variation of model simulated and observed MWS $\left(\mathrm{ms}^{-1}\right)$ of TC Roanu by using five different CP schemes i.e., KF, BMJ, GFE, G3E and GD is displayed in Fig. 5. The model simulated MWS are found at the ideal atmospheric altitude of $10 \mathrm{~m}$. The IMD observed MWS is $23 \mathrm{~ms}^{-1}$ at 0600 UTC of 21 May 2016. The model simulated MWS of $43,34,30,34$ and $25 \mathrm{~ms}^{-1}$ are found at 1200, 1200, 0000, 1200 and 0000 UTC of 21 May 2016 for KF, BMJ, GFE, G3E and GD schemes respectively. From Fig. 5 it is found that, the model simulated MWS for all CP schemes shows the higher value than the observed value.

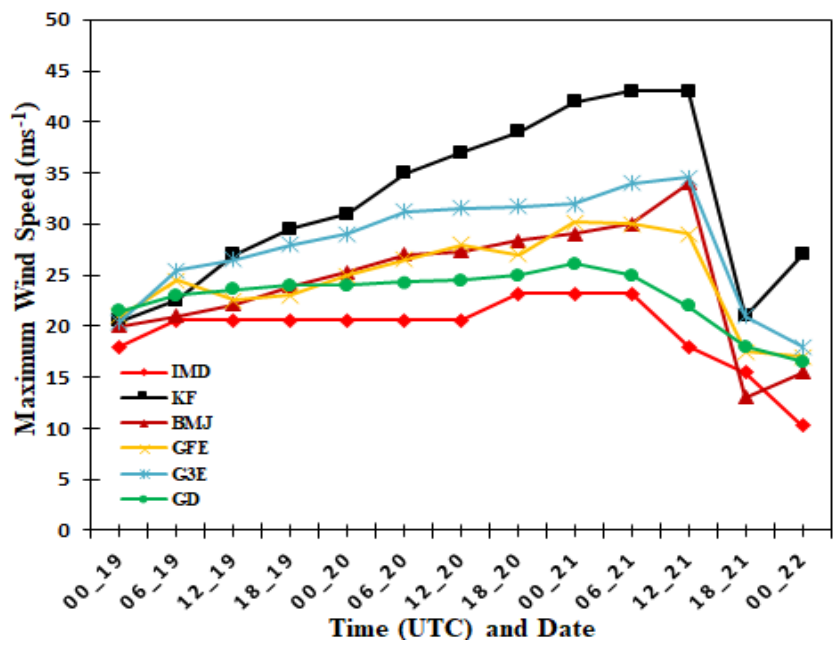

Fig. 5. Variation of observed and model simulated MWS $\left(\mathrm{ms}^{-1}\right)$ with time for five different $\mathrm{CP}$ schemes.

It is also observed that (Table-3), the model simulated MWS shows the deviation of 187, 148, 130, 148 and 109\% for KF, BMJ, GFE, G3E and GD respectively from the observed value. The KF, BMJ, GFE, G3E and GD schemes have $87,48,30,48$ and $9 \%$ more intense than the observed value of IMD. The MSLP simulated time are almost similar with the MWS simulated time for different CP schemes i.e., $\mathrm{KF}, \mathrm{BMJ}, \mathrm{GFE}, \mathrm{G} 3 \mathrm{E}$ and GD. 
The RMSE and MAE has also been calculated for the model simulated and observed MSLP and MWS. These contributes a very good complete measures of model performance. The model with a lower RMSE and MAE (near to zero) has a good ability of prediction but where the value is maximum the model prediction shows more deviation there from the observed value. The RMSE and MAE both are indifferent to the direction of errors ${ }^{24,25}$. From Table 3 it is observed that, the RMSE and MAE of MSLP is found minimum for GD and BMJ schemes, which indicates that these schemes gives the better prediction of MSLP than the other schemes. The RMSE and MAE of MWS is found minimum for GD and GFE schemes, which indicates that these schemes gives the better prediction of MWS than the other schemes. It is observed that, the CP schemes wise RMSE is larger than the MAE. In case of RMSE, errors are squared earlier they are averaged. So comparatively the RMSE provides a large weight to high errors. The RMSE would be suitable much when large errors are mainly undesirable.

Table 3. The deviation of MWS and RMSE, MAE of both MSLP and MWS.

\begin{tabular}{|l|l|l|l|l|l|}
\hline \multirow{2}{*}{$\begin{array}{l}\text { CP } \\
\text { schemes }\end{array}$} & \multirow{2}{*}{$\begin{array}{l}\text { MWS } \\
\text { Deviation } \\
(\%)\end{array}$} & \multicolumn{2}{l|}{ MSLP $(\mathrm{hPa})$} & \multicolumn{2}{l|}{ MWS $\left(\mathrm{ms}^{-1}\right)$} \\
\cline { 3 - 6 } & 187 & 21.91 & 17.20 & 14.28 & 12.53 \\
\hline KF & RMSE & MAE & RMSE & MAE \\
\hline BMJ & 148 & 14.11 & 11.36 & 6.35 & 5.15 \\
\hline GFE & 130 & 21.81 & 18.21 & 5.72 & 5.12 \\
\hline G3E & 148 & 23.54 & 20.29 & 9.03 & 8.37 \\
\hline GD & 109 & 12.10 & 9.20 & 3.48 & 3.30 \\
\hline
\end{tabular}

Latent Heat Flux (LHF) at the surface

The time variation of model simulated area averaged LHF $\left(\mathrm{Wm}^{-2}\right)$ at the surface valid for $0000 \mathrm{UTC}$ of 19 May to 0000 UTC of 22 May 2016 using KF, BMJ, GFE, G3E and GD schemes is shown in Fig. 6. When the evaporation occurs between the air-sea boundaries, some energy transfer towards the upward direction as a latent heat and thus water vapor increases in the air. For atmospheric circulation it acts as a key energy source ${ }^{26}$. The maximum LHF is about 1289,1331 and $1016 \mathrm{Wm}^{-2}$ at 1200,1200 and 0000 UTC of 21 May for KF, G3E and GD scheme respectively, $1206 \mathrm{Wm}^{-2}$ at $0000 \mathrm{UTC}$ of 20 May for BMJ scheme and $1308 \mathrm{Wm}^{-2}$ at 1800 UTC of 19 May for GFE scheme. The KF and G3E schemes produce stronger surface LHF when the wind speed is maximum. The BMJ and GFE schemes also produce stronger surface LHF not at the same time of the MWS but before the time of MWS found. The BMJ and GD schemes show the intermediate values of surface LHF. The intensity of TC depends on the LHF released and more intensified TC is observed with greater $\mathrm{LHF}^{27}$. The intensity of the TC Roanu depends on the surface LHF and maximum when LHF is maximum for most of the CP schemes.

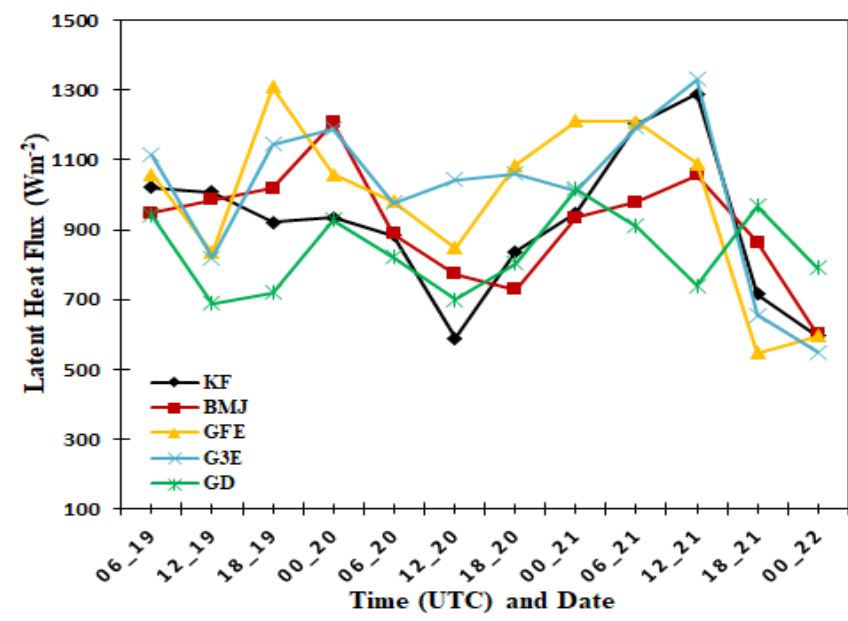

Fig. 6. Variation of model simulated area averaged LHF $\left(\mathrm{Wm}^{-2}\right)$ at the surface with time for five different $\mathrm{CP}$ schemes.

Convective Available Potential Energy (CAPE)

The variation of model simulated area averaged CAPE $\left(\mathrm{Jkg}^{-}\right.$ ${ }^{1}$ ) with time valid for 0000 UTC of 19 May to 0000 UTC of 22 May 2016 by using five different $\mathrm{CP}$ schemes i.e., KF, BMJ, GFE, G3E and GD is shown in Fig. 7.The CAPE is efficiently the constructive buoyancy of an air piece.It indicates the vulnerability of the atmosphere, so it is very important parameter for severe weather prediction. The dry air produces lower $\mathrm{CAPE}^{28}$. The CAPE is found maximum of about $>6660,>6250,>6900,>6700$ and $>6700 \mathrm{Jkg}^{-1}$ at 0000 UTC of 22 May for KF, BMJ, GFE, G3E and GD schemes respectively.

It is clearly understood from Fig. 7 that, the CAPE is greater than $4000 \mathrm{Jkg}^{-1}$ for all CP schemes at 0000 UTC of 22 May, which indicates the extremely unstable condition of atmosphere for the intensification of TC Roanu at that time $^{29}$. The CAPE is found minimum of about 3732, 3278, 3639, 3732 and 3716 at 0000, 0600, 0600, 0000 and 0000 UTC of 19 May for KF, BMJ, GFE, G3E and GD schemes respectively.

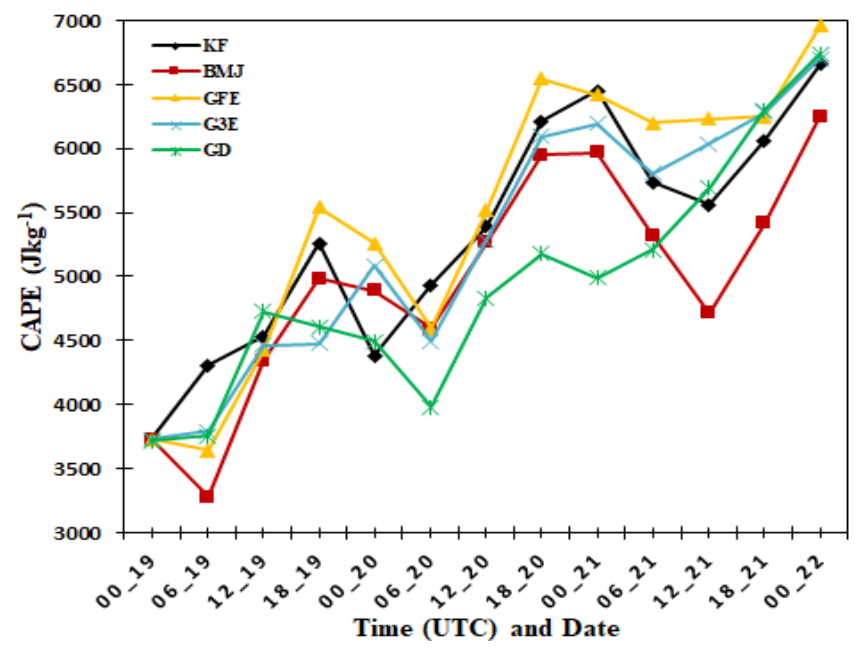

Fig. 7. Variation of model simulated area averagedCAPE $\left(\mathrm{Jkg}^{-1}\right)$ with time for five different CP schemes. 
At these times the atmosphere shows strong instability for the intensification of TC (i.e., CAPE is in between 2500$\left.4000 \mathrm{Jkg}^{-1}\right)^{29}$. Though, the CAPE is found $>3000 \mathrm{Jkg}^{-1}$ everytime for all CP schemes, but the maximum amount of CAPE is found near the time of landfall (14 hours later) related to the IMD detected data. Also, the maximum amount of CAPE is found at 0000 UTC of 21 May for KF and BMJ, at $1800 \mathrm{UTC}$ of 20May for GFE, at $1800 \mathrm{UTC}$ of 21 May for G3E and GD schemes. The higher value of CAPE indicates the higher wind speed and moisture at that time.

\section{Accumulated total cumulus rainfall}

The time variation of model simulated accumulated total cumulus rainfall $(\mathrm{mm})$ related to TC Roanu valid for 0000 UTC of 19 May to 0000 UTC of 22 May 2016 using KF, BMJ, GFE, G3E and GD schemes is shown in Fig. 8. According to the IMD observation ${ }^{15}$ the coastal Andhra Pradesh and neighboring regions of north coastal Tamil Nadu on $19^{\text {th }}$ May, the north Andhra Pradesh, coastal Odisha and coastal West Bengal on $20^{\text {th }}$ May, the north coastal Odisha, coastal West Bengal and Bangladesh on $21^{\text {st }}$ May have experienced a lot of precipitation which exceeds the value of $120 \mathrm{~mm}$. The model simulated accumulated total rainfall has the increasing pattern with time for all $\mathrm{CP}$ schemes. The accumulated total rainfall for KF scheme has more than 114, 270 and $399 \mathrm{~mm}$ at 19, 20 and 21 May respectively and maximum value of more than $400 \mathrm{~mm}$ at 0000 UTC of 22 May. The rainfall for GFE scheme has more than 155, 230 and $260 \mathrm{~mm}$ at 19, 20 and 21 May respectively and has the maximum value of more than 300 $\mathrm{mm}$ at 0000 UTC of 22 May. The G3E scheme simulated rainfall is more than 139, 198 and $230 \mathrm{~mm}$ at 19, 20 and 21 May respectively and has maximum value of more than 238 $\mathrm{mm}$ at 0000 UTC of 22 May.

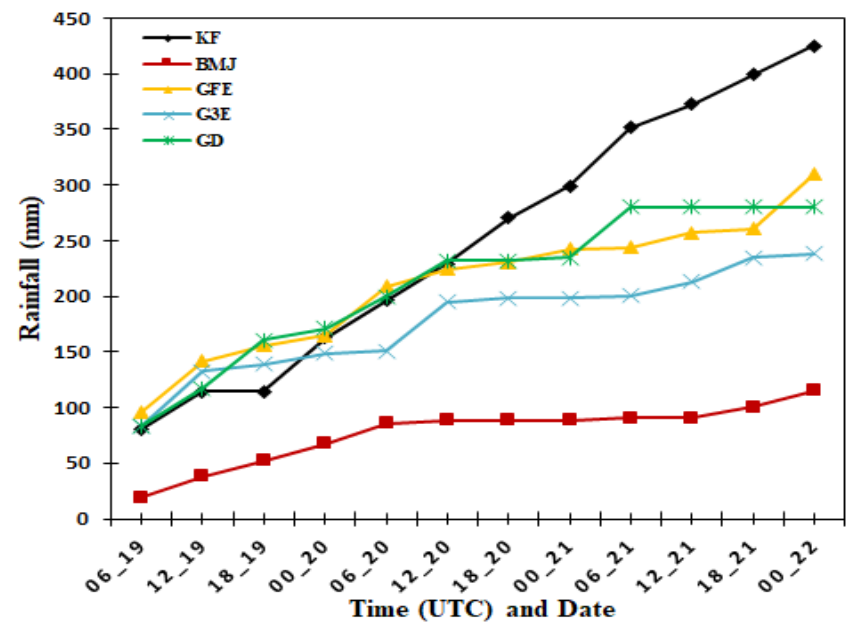

Fig. 8. The time variation of model simulated accumulated rainfall $(\mathrm{mm})$ for five different $\mathrm{CP}$ schemes.

The GD scheme gives more than 160, 230 and $280 \mathrm{~mm}$ of rainfall at 19, 20 and 21 May respectively and has maximum of more than $280 \mathrm{~mm}$ at 0000 UTC of 22 May. The accumulated total rainfall for BMJ scheme has the lowest value than the other CP schemes. For BMJ scheme the simulated rainfall is about 52, 88 and $100 \mathrm{~mm}$ at 19, 20 and 21 May respectively and has maximum of about 115 $\mathrm{mm}$ at 0000 UTC of 22 May. All the schemes show the overestimated rainfall than that of the IMD observed rainfall except $\mathrm{BMJ}$ scheme.

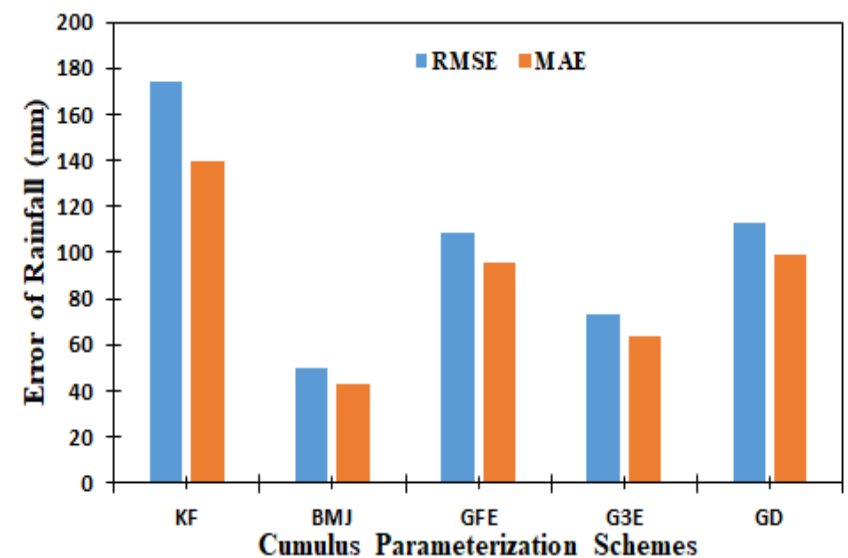

Fig. 9. The RMSE and MAE of rainfall for five different CP schemes.

Fig. 9 shows the RMSE and MAE of rainfall for five different CP schemes. The maximum RMSE and MAE of rainfall is found for $\mathrm{KF}$ and minimum is found for $\mathrm{BMJ}$ scheme, which indicates that the BMJ scheme gives the better prediction of rainfall than the other schemes. The $\mathrm{CP}$ schemes wise RMSE is larger than the MAE. In case of RMSE, errors are squared earlier they are averaged. So comparatively the RMSE provides a large weight to high errors. The RMSE would be suitable much when large errors are mainly undesirable.

\section{Water Vapor Mixing Ratio (WVMR)}

The time variation of model simulated area average WVMR $(\mathrm{g} / \mathrm{kg})$ at $850 \mathrm{hPa}$ level valid for $0000 \mathrm{UTC}$ of 19 May to 0000 UTC of 22 May 2016 by using five different CP schemes i.e., KF, BMJ, GFE, G3E and GD is shown in Fig. 10. The area average WVMR is found maximum 21.54 $\mathrm{g} / \mathrm{kg}$ for KF scheme at $1200 \mathrm{UTC}$ of 21 May and minimum $17.5 \mathrm{~g} / \mathrm{kg}$ for BMJ scheme at 0000 UTC of 22 May. Starting from the preliminary state of 0000 UTC of 19 May, the temporal distribution of area average WVMR has increased continuously with the progression of time or with the development of the system for all CP schemes except for BMJ at 0000 UTC of 20 May, for G3E at 1800 UTC of 19 May. The WVMR is also found maximum 21, 21.51 and $21.08 \mathrm{~g} / \mathrm{kg}$ at 1200,0600 and $0000 \mathrm{UTC}$ of 21 May for BMJ, GFE and G3E respectively.The GD scheme shows the discontinuity of WVMR for different time and GD scheme shows the more deviation from the other $\mathrm{CP}$ schemes. The maximum WVMR is found after 2 hours of IMD observed landfall time (1000 UTC of 21 May) for KF and BMJ schemes, before 4 hours of IMD observed landfall time for GFE scheme and before 10 hours of IMD observed landfall time for G3E scheme. The maximum WVMR indicates the maximum latent heat present in the 
atmosphere as well as the maximum convective activity. Except GD scheme all the other schemes simulate very good WVMR and shows the very good convective activity or cyclonic intensity at that time of maximum WVMR.

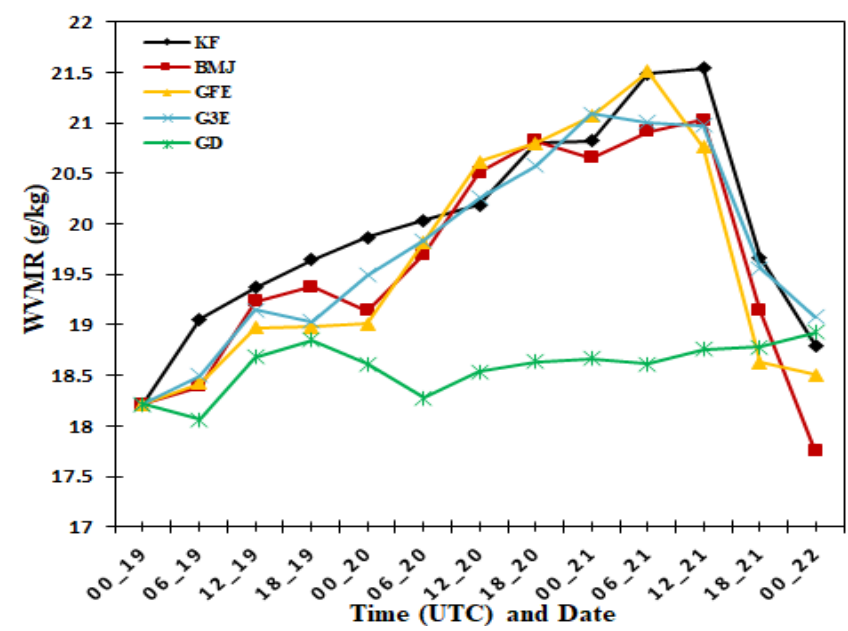

Fig. 10. Variation of model simulated area average WVMR $(\mathrm{g} / \mathrm{kg})$ at $850 \mathrm{hPa}$ level with time for five different $\mathrm{CP}$ schemes.

\section{Conclusions}

The TC Roanu has been selected to analyze the influence of various $\mathrm{CP}$ schemes on the prediction of the track pattern, intensity in terms of MSLP and MWS, LHF, MCAPE, MCIN, rainfall and WVMR. According to our current research work, the subsequent conclusions can be made as follows:

- The average track error is maximum for GD (338 km) and minimum for $\mathrm{KF}(123.20 \mathrm{~km})$ scheme.The landfall position error is minimum for BMJ $(21.89 \mathrm{~km})$ and maximum for G3E $(132.80 \mathrm{~km})$ scheme. The landfall time was delayed only 3.5, 5.0, 1.5 and 2.5 hours for KF, BMJ, GFE and G3E schemes respectively. However, there are some errors in the locations with respect to time which displays few delays in landfall but all the schemes are very much capable to found the right track of TC Roanu except GD scheme.

- The MSLP and MWS shows higher deviation for KF and lower for GD scheme. The RMSE, MAE of MSLP and MWS are smaller for GD and larger for KF, G3E schemes. Though, the GD scheme shows the better simulation but the intensity in terms of pressure fall and MWS are much higher for KF scheme than that of observed intensity.

- The maximum RMSE and MAE of rainfall is found for $\mathrm{KF}$ and minimum for BMJ scheme, which indicates that the BMJ scheme gives the better prediction of rainfall than the other schemes.

- The KF and G3E schemes produce stronger surface LHF (1289-1331 $\mathrm{Wm}^{-2}$ ) when the wind speed is maximum and just 2 hours later of landfall time.
- All the scheme simulates the significant amount of CAPE at very similar time. At this time the weather shows more instability for the intensification of TC Roanu.

- The significant amount of WVMR (21-21.6 g/kg) is found for all the CP schemes except GD scheme near to the landfall time.

Overall, it can be specified that the KF, BMJ, GFE and G3E schemes simulate the better intensity and track of $\mathrm{TC}$ Roanu.

\section{Acknoledgement}

The authors gratefully acknowledge the NCEP/NCAR for providing WRF-ARW modeling system and their reanalysis data sets. The authors are thankful to India Meteorological Department (IMD) for providing required observed meteorological data. The authors are also grateful to Department of Physics, Khulna University of Engineering \& Technology (KUET) for providing laboratory facilities in atmospheric physics laboratory.

\section{References}

1. Hossain, M. Z., M. T. Islam, T. Sakai, and M. Ishida, 2008. Impact of tropical cyclones on rural infrastructures in Bangladesh. Agricultural Engineering International: CIGR Journal, 10, Invited Overview No. 2.

2. Emanuel, K.,2005. Increasing destructiveness of tropical cyclones over the past 30 years. Nature, 436, 686 .

3. Akhter, M. A. E., M. M. Alam, and M. A. K. Mallik,2016. Simulation of the Structure and Track of the Tropical Cyclone Sidr using Numerical Models. Journal of Scientific Research, 8, 129-147.

4. India Meteorological Department (IMD) cyclone intensity scale.

http://www.rsmenewdelhi.imd.gov.in/images/pdf/cycloneawareness/terminology/faq.pdf

5. Akter, N., and K. Tsuboki, 2014. Role of synoptic-scale forcing in cyclogenesis over the Bay of Bengal. Climate dynamics, 43, 2651-2662.

6. Kikuchi, K., and B. Wang, 2010. Formation of tropical cyclones in the northern Indian Ocean associated with two types of tropical intraseasonal oscillation modes. Journal of the Meteorological Society of Japan, 88, 475-496.

7. Mandal, M., U. C. Mohanty, and S. Raman, 2004. A study on the impact of parameterization of physical processes on prediction of tropical cyclones over the Bay of Bengal with NCAR/PSU mesoscale model. Natural Hazards, 31, 391414.

8. Wang, W. and N. L. Seaman, 1997. A comparison study of convective parameterization schemes in a mesoscale model. Monthly Weather Review, 125, 252-278.

9. Islam, M. J., I. Ashik, I. M. Syed, S. M. Q. Hassan, and M. I. Ali, 2019. The sensitivity of Microphysical Parameterization Schemes on the Prediction of Tropical Cyclone Mora Over the Bay of Bengal using WRF-ARW Model. Dhaka Univ. J. Sci., 67, 33-40. 
10. Litta, A. J., S. M. Idicula, and U. C. Mohanty,2011. A comparative study of convective parameterization schemes in WRF-NMM model. International Journal of Computer Applications, 33, 32-39.

11. Osuri, K. K., U. C. Mohanty, A. Routray, M. A. Kulkarni, and M. Mohapatra, 2012. Customization of WRF-ARW model with physical parameterization schemes for the simulation of tropical cyclones over North Indian Ocean. Natural Hazards, 63, 1337-1359.

12. Mohandas, S., and R. Ashrit, 2014. Sensitivity of different convective parameterization schemes on tropical cyclone prediction using a mesoscale model. Natural hazards, $\mathbf{7 3}$, 213-235.

13. Sikder, S. and F. Hossain,2016. Assessment of the weather research and forecasting model generalized parameterization schemes for advancement of precipitation forecasting in monsoon-driven river basins. Journal of Advances in Modeling Earth Systems, 8, 1210-1228.

14. Skamarock, W. C., J. B. Klemp, J. Dudhia, D. O. Gill, D. M. Barker, M. G. Duda, and J. G. Powers,2008. A description of the advanced research WRF version 3, NCAR Technical Note. National Center for Atmospheric Research: Boulder, CO, USA.

15. Cyclonic Storm,'Roanu' over the Bay of Bengal (17-22 May 2016): A Report, IMD.

16. Kain, J. S., 2004. The Kain-Fritsch convective parameterization: An update. J. Appl. Meteor.,43, 170-181.

17. Betts, A. K. andM. J. Miller, 1986. A new convective adjustment scheme. Part II: Single column tests using GATE wave, BOMEX, ATEX and arctic air-mass data sets. Quarterly Journal of the Royal Meteorological Society, 112, 693-709.

18. Janjic, Z. I., 1994. The step-mountain eta coordinate model: Further developments of the convection, viscous sublayer, and turbulence closure schemes. Mon. Wea. Rev.,122, 927945.

19. Grell, G. A. and S. R. Freitas,2014. A scale and aerosol aware stochastic convective parameterization for weather and air quality modeling. Atmos. Chem. Phys., 14, 5233-5250.
20. Grell, G. A., 1993. Prognostic evaluation of assumptions used by cumulus parameterizations. Monthly Weather Review, 121, 764-787.

21. Grell, G. A. and D. Dévényi,2002. A generalized approach to parameterizing convection combining ensemble and data assimilation techniques. Geophysical Research Letters, 29, $38-1$.

22. Lim, K. S. S. and S. Y. Hong,2010. Development of an effective double-moment cloud microphysics scheme with prognostic cloud condensation nuclei (CCN) for weather and climate models. Monthly weather review, 138, 1587-1612.

23. Mallik, M. A. K., M. N. Ahasan, and M. A. M Chowdhury, 2015. Simulation of track and landfall of tropical cyclone Viyaru and its associated strom surges using NWP models. Am J Mar Sci., 3, 11-21.

24. El Afandi, G., M. Morsy, and F. El Hussieny, 2013. Heavy rainfall simulation over Sinai Peninsula using the weather research and forecasting model. International Journal of Atmospheric Sciences, 2013, 1-11.

25. Kondowe, A. L., 2014. Impact of Convective Parameterization Schemes on the Quality of Rainfall Forecast over Tanzania Using WRF-Model. Natural Science, 6, 691699.

26. Ren, D., M. Lynch, L. M. Leslie, and J. Lemarshall, 2014. Sensitivity of tropical cyclone tracks and intensity to ocean surface temperature: Four cases in four different basins. Tellus A: Dynamic Meteorology and Oceanography, 66, 24212.

27. Zhu, T. and D. L. Zhang, 2006. Numerical simulation of Hurricane Bonnie (1998). Part II: Sensitivity to varying cloud microphysical processes. Journal of the atmospheric sciences, 63, 109-126.

28. Yin, J., J. D. Albertson, J. R. Rigby, and A. Porporato, 2015. Land and atmospheric controls on initiation and intensity of moist convection: CAPE dynamics and LCL crossings. Water Resources Research, 51, 8476-8493.

29. Thompson, R., 2005. Explanation of SPC severe weather parameters. Storm Prediction Center, National Oceanic and Atmospheric Administration.

https://www.spc.noaa.gov/sfctest/help/sfcoa.html 